\title{
Uso del software GeoGebra: Análisis del proceso de aprendizaje de los conceptos de poliedro
}

Ana Maria Mota Oliveira Scalabrin anamscalabrin@gmail.com https://orcid.org/0000-0001-5328-9782

Solange Mussato

solangemussato1@yahoo.com.br https://orcid.org/0000-0001-5960-0375

Universidade Estadual de Roraima (UERR, Brasil)

Recibido: 31/05/2020 Aceptado: 06/07/2020

\begin{abstract}
Resumen
Este artículo describe parte de los resultados de una investigación de maestría, cuyo objetivo era investigar las contribuciones del software GeoGebra 3D a los procesos de enseñanza y aprendizaje del contenido de Geometría Espacial en la escuela secundaria, siguiendo los supuestos teóricos del modelo Van Hiele. En cuanto a los procedimientos metodológicos, la investigación se desarrolló desde la perspectiva del enfoque cualitativo, a través de la investigación-acción, en una clase del segundo grado de la escuela secundaria de una escuela pública ubicada en Boa Vista, Roraima, Brasil. Dicha intervención permitió la producción de datos que se registraron a través de cuestionarios, el guión de observación del investigador, los registros fotográficos, los archivos digitales creados con el software GeoGebra y los registros escritos de las actividades propuestas. Los resultados mostraron que el uso del software GeoGebra 3D contribuyó efectivamente a promover el avance del pensamiento geométrico de los estudiantes investigados, en relación con los conceptos de poliedros, desde el nivel 1 (visualización) hasta el nivel 4 (deducción formal) del Modelo Van Hiele.
\end{abstract}

Palabras clave: Tecnología educativa; Escuela secundaria; Conceptos Geométricos; Modelo Van Hiele.

\section{Uso do software GeoGebra: Análise do processo de aprendizagem dos conceitos de poliedros}

\section{Resumo}

O presente artigo descreve parte dos resultados de uma pesquisa de mestrado, cujo objetivo foi investigar as contribuições do software GeoGebra 3D para os processos de ensino e de aprendizagem de conteúdos de Geometria Espacial no Ensino Médio, seguindo os pressupostos teóricos do Modelo de Van Hiele. Quanto aos procedimentos metodológicos, a pesquisa foi desenvolvida sob a perspectiva da abordagem qualitativa, por meio da pesquisaação, em uma turma da $2^{a}$ série do Ensino Médio de uma escola pública localizada em Boa Vista, Roraima, Brasil. Tal intervenção possibilitou a produção dos dados que foram registrados por meio de questionários, roteiro de observação da pesquisadora, registros fotográficos, arquivos digitais construídos com o software GeoGebra e registros escritos das 
atividades propostas. Os resultados apontaram que o uso do software GeoGebra 3D contribuiu efetivamente para promover o avanço do pensamento geométrico dos alunos investigados, em relação aos conceitos de poliedros, desde o nível 1 (visualização) até o nível 4 (dedução formal) do Modelo de Van Hiele.

Palavras-chave: Tecnologia Educacional; Ensino Médio; Conceitos Geométricos; Modelo de Van Hiele.

\title{
Use of GeoGebra Software: Analysis of the polyeder concept learning process
}

\begin{abstract}
This article describes part of the results of a Master's degree, whose objective was to investigate how contributions of the GeoGebra 3D software to the teaching and learning processes of Spatial Geometry content in high school, following the theoretical assumptions of the Van Hiele Model. As for the methodological procedures, a research was developed from a perspective of qualitative approach, through action research, in a class of the 2 nd grade of High School of a public school located in Boa Vista, Roraima, Brazil. This intervention enabled the of data production that were registered through questionnaires, researchers' observation itinerary, photographic records, digital files built with the GeoGebra software and written records of applied activities. The results indicated for the use of the GeoGebra 3D software effectively contributed to promote the advancement of students' scientific thinking, in relation to the concepts of politicians, from level 1 (answers) to level 4 (formal deduction) of the Van Hiele Model.
\end{abstract}

Keywords: Educational Technology; High school; Geometric Concepts; Van Hiele Model.

\section{Introdução}

Este artigo faz parte de uma pesquisa realizada em um curso de mestrado profissional, desenvolvida no âmbito do Programa de Pós-Graduação em Ensino de Ciências da Universidade Estadual de Roraima (UERR), cuja dissertação foi intitulada Geometria Espacial com o software GeoGebra 3D: Análise dos processos de ensinar e de aprender no Ensino Médio. A pesquisa teve como objetivo geral investigar as contribuições do software GeoGebra 3D para os processos de ensino e de aprendizagem de conteúdos de Geometria Espacial no Ensino Médio, seguindo os pressupostos teóricos do Modelo de Van Hiele.

A investigação foi norteada pela seguinte questão: De que forma o uso do software GeoGebra pode contribuir para os processos de ensino e de aprendizagem de conteúdos de Geometria Espacial no Ensino Médio? Durante a elaboração do trabalho de investigação foi necessário escolher um embasamento teórico que apresentasse subsídios para a análise dos 
dados produzidos. Desta maneira, a pesquisa foi desenvolvida e embasada pela Teoria de Desenvolvimento dos Níveis de Pensamento Geométrico de Van Hiele. Essa teoria teve origem nas teses de doutorado de Dina Van Hiele-Geldof e de seu marido, Pierre Van Hiele, na Universidade de Utrecht, na Holanda, em 1957 (Villiers, 2010).

Para a consolidação da investigação aqui descrita, elaboramos e desenvolvemos um Produto Educacional (PE), com uma sequência de atividades sobre poliedros, prismas e pirâmides, utilizando o software GeoGebra. Nesse artigo, considerando parte dos resultados obtidos na pesquisa, discutiremos de que forma o processo de ensino dos conceitos de poliedros regulares possibilitou o avanço do pensamento geométrico dos alunos, desde o nível 1 (visualização) até o nível 4 (dedução formal) do Modelo de Van Hiele.

Acreditamos que novas alternativas surgem para os processos de ensino e de aprendizagem da Matemática com o uso de tecnologias digitais (TD), proporcionando aos professores possibilidades de ampliar os métodos de ensino e, aos alunos, possibilidades de melhorar a aprendizagem. Contudo, isso envolve necessariamente uma mudança na prática pedagógica do professor, já que este passa a ter a função de planejar e mediar o ensino com tarefas desafiadoras, que ofereçam autonomia ao aluno para se envolver em explorar a atividade com o uso de TD, e, por conseguinte, a apropriação dos conceitos com significado.

Nesse sentido, Bonotto e Bisognin (2015, p. 2) destacam que "O grande desafio dos professores não é somente utilizar as tecnologias em sala de aula, mas sim, tornar a aula mais envolvente, interativa, criativa e capaz de produzir significados ao aluno por meio da utilização da tecnologia". Assim, consideramos que o uso de softwares educacionais nos processos de ensino e de aprendizagem de conteúdos de Geometria Espacial pode contribuir em muitos fatores, especificamente no que se refere à visualização das figuras tridimensionais.

É importante salientar que a capacidade de visualizar pode ser desenvolvida à medida que se forneça ao aluno material de apoio didático baseado em elementos concretos, representativos do objeto geométrico em estudo. Destacamos que explorar os aspectos visuais do GeoGebra com atividades pedagógicas que ofereçam meios para a investigação e experimentação com tecnologias, assume uma dimensão heurística, sendo apropriada aos cenários de ensino e aprendizagem de Matemática (Borba et al., 2016). 
No atual contexto, muitos recursos tecnológicos estão disponíveis para auxiliar o professor em sua prática pedagógica. No campo do ensino da Matemática, Borba et al. (2016, p. 17) destacam que "as dimensões da inovação tecnológica permitem a exploração e o surgimento de cenários alternativos para a educação e, em especial, para o ensino de Matemática". Nesse caso, pontuamos que o uso de recursos tecnológicos deve permitir criar ambientes de aprendizagem que façam surgir novos caminhos para os papéis que alunos e professores podem assumir neste contexto de ensino e de aprendizagem.

Assim, em meio às facilidades de acesso aos mais variados recursos tecnológicos que estão disponíveis para auxiliar o professor em sua prática pedagógica, pareceu-nos pertinente e interessante investigar a contribuição do uso do software GeoGebra 3D para os processos de ensino e de aprendizagem de conteúdos de Geometria Espacial no Ensino Médio.

O GeoGebra escolhido para esta investigação é um software de matemática dinâmica, de acesso livre, que possibilita a criação de pontos, retas, planos e construções de objetos espaciais, como prismas, pirâmides, cilindros, cones, esferas, etc. Este ambiente permite que os alunos visualizem os objetos construídos de maneira diferente do que estão habituados a observar nos livros didáticos. Giraldo (2012) afirma que as construções geométricas reproduzidas na tela do computador desses ambientes são munidas de ferramentas que apresentam grande vantagem sobre as desenvolvidas com lápis e papel, pois quando concluídas, é possível alterar com praticidade alguns elementos (em geral, por meio do arrastar do mouse) e observar as modificações decorrentes.

De fato, ao explorar um objeto construído no GeoGebra 3D, determinada representação aparece como uma das possíveis posições que o objeto pode assumir, e isto proporciona significado e movimento às imagens mentais que são criadas pelo aluno. Além do mais, os alunos podem interagir com o objeto construído e assim, formar imagens mentais mais significativas. Assim sendo, as possibilidades que o GeoGebra 3D oferece para explorar e investigar os sólidos geométricos podem modificar o tipo de atividades que são propostas em sala de aula, bem como transformar a natureza do conhecimento matemático.

Nesse sentido, Pereira (2012, p. 32) esclarece que "As características do GeoGebra potencializam a constituição de cenários para investigação, nos quais o aluno é capaz de experimentar situações em um processo dinâmico". De tal modo, a possibilidade de uso de um 
software que apresenta multiplataforma pode favorecer a construção de um ambiente mais propício para a aprendizagem da Matemática. Através de rotações no objeto construído, por exemplo, pode-se explorar situações virtuais que acionam habilidades de visualização muito similares àquelas decorrentes da manipulação de objetos 3D no espaço real.

Explanaremos na próxima seção deste artigo sobre o Modelo de Van Hiele e seu papel no desenvolvimento do pensamento geométrico dos estudantes, considerando que eles foram essenciais para a análise da investigação realizada. Traremos, em seguida, os delineamentos metodológicos que conduziram a pesquisa, bem como o contexto onde foi realizada. Apresentaremos, então, um recorte com a análise do processo de aprendizagem dos conceitos de poliedros regulares e, por fim, teceremos algumas considerações a respeito do trabalho realizado.

\section{O Modelo de Van Hiele para o desenvolvimento do pensamento geométrico}

Nessa seção, faremos um breve relato sobre o Modelo de Van Hiele e seu papel no desenvolvimento do pensamento geométrico dos estudantes. Esse Modelo, também denominado de Teoria do Desenvolvimento do Pensamento Geométrico, como pontuam Abar e Cotic (2014), é um guia para a aprendizagem da geometria proposto nas teses de doutorado do casal Pierre e Dina Van Hiele, na Universidade de Utrecht, Holanda em 1957.

Para Nasser (1990), um ponto positivo do Modelo de Van Hiele foi o fato de ter se originado em sala de aula quando o casal Van Hiele observou as dificuldades de seus alunos ao resolverem tarefas em geometria. Quanto às propostas apresentadas pelo casal Van Hiele, Villiers (2010, p. 400) destaca que:

Enquanto a tese de Pierre tentava, principalmente, explicar o porquê os alunos tinham problemas ao aprender geometria (sob tal aspecto, ela era explicativa e descritiva), a tese de Dina versava sobre um experimento educacional e, sob tal aspecto, é mais prescriptiva com relação à ordenação do conteúdo de geometria e atividades de aprendizado dos alunos.

Como Dina faleceu logo após o término da tese de doutorado, foi Pierre quem mais tarde desenvolveu e disseminou a teoria em publicações posteriores. Assim, apoiado em experiências educacionais esse modelo além de orientar a formação, também nos permite compreender as habilidades do aluno em geometria (Meira, 2015). 
De acordo com Alves e Sampaio (2010), Villiers (2010), Abar e Cotic (2014), Nasser e Vieira (2015), entre outros pesquisadores, o Modelo de Van Hiele apresenta cinco níveis de compreensão para o desenvolvimento do raciocínio geométrico. "Estes níveis informam quais são as características do processo de pensamento dos estudantes em geometria" (Alves \& Sampaio, 2010, p. 70).

As características gerais de cada nível de compreensão do Modelo Van Hiele e suas respectivas características são apresentadas no Quadro 1.

Quadro 1: Níveis da Teoria de Van Hiele

\begin{tabular}{|l|l|}
\hline Níveis de Compreensão & \multicolumn{1}{c|}{ Características } \\
\hline $\begin{array}{l}\text { Nível 1: Visualização ou } \\
\text { reconhecimento }\end{array}$ & $\begin{array}{l}\text { O aluno utiliza somente a informação visual, não reconhece partes ou elementos } \\
\text { das figuras embora reproduzam e reconheçam figuras individuais. }\end{array}$ \\
\hline Nível 2: Análise & $\begin{array}{l}\text { O aluno descreve as partes das figuras e enuncia as propriedades definidas de } \\
\text { forma experimental. }\end{array}$ \\
\hline $\begin{array}{l}\text { Nível 3: Ordenação ou } \\
\text { classificação }\end{array}$ & $\begin{array}{l}\text { O aluno executa classificações lógicas das figuras por suas propriedades, começa } \\
\text { o desenvolvimento da capacidade de raciocínio rigoroso. }\end{array}$ \\
\hline Nível 4: Dedução formal & $\begin{array}{l}\text { O aluno compreende a lógica formal de raciocínio, podem realizar demonstrações } \\
\text { de maneiras diferentes, propõe conjecturas. }\end{array}$ \\
\hline Nível 5: Rigor & Desenvolve o raciocínio matemático formal. \\
\hline
\end{tabular}

Fonte: Adaptado de Abar e Cotic (2014, p. 54-55)

Como se observa no Quadro 1, podemos constatar que o Modelo de Van Hiele leva o aluno, a partir do nível de reconhecimento das formas geométricas básicas e de suas características, seguir os níveis da análise, ordenação ou classificação, dedução formal e, finalmente atingir o nível do rigor, passando a entender e relacionar conceitos geométricos abstratos. Meira (2015) pontua que os avanços de um nível para outro podem ocorrer por meio de atividades planejadas, uma vez que o avanço dos níveis de compreensão depende mais especificamente de uma aprendizagem adequada à experiência do aluno.

Percebe-se assim, que as ideias preliminares desse Modelo estabelecem que os alunos avancem na aprendizagem dos conteúdos geométricos, a partir de uma sequência de níveis de compreensão de conceitos. Dessa forma, o avanço entre esses níveis de compreensão se dá a partir de ordem hierárquica, na qual o estudante passa de um nível mais simples para um mais elaborado.

Nesse sentido, Abar e Cotic (2014) salientam que cada nível da teoria de Van Hiele é construído sobre o anterior como uma sequência de abordagens intuitivas, para raciocínio cada vez mais dedutivo a partir da experiência própria. Para Nasser (1990), os alunos passam pelos 
níveis em ordem consecutiva, mas não no mesmo ritmo. Diante do exposto, percebemos que é possível encontrar alunos em diferentes níveis na mesma turma. Ou seja, o aluno que está raciocinando num determinado nível pode não compreender alguns termos usados em uma linguagem na qual os níveis são mais avançados.

Além dos níveis de compreensão, no Modelo de Van Hiele são definidas cinco fases que devem ser vivenciadas pelos estudantes para que ocorra progresso de níveis de aprendizagem e devem ser favorecidas e/ou encorajadas pelo professor (Nasser, 1990). Para essa autora, o que promove a evolução do pensamento geométrico é a vivência com atividades adequadas, que ao serem trabalhadas em sala de aula favorecem a aprendizagem geométrica.

O Quadro 2 relaciona as fases de aprendizagem necessárias para organizar o ensino de acordo com o modelo sugerido por Van Hiele.

Quadro 2: Fases de Aprendizagem do Modelo de Van Hiele

\begin{tabular}{|c|l|}
\hline $\begin{array}{c}\text { Fases de } \\
\text { aprendizagem }\end{array}$ & \multicolumn{1}{c|}{ Características } \\
\hline $\begin{array}{c}\text { Questionamento ou } \\
\text { Informação } \\
\text { (fase 1) }\end{array}$ & $\begin{array}{l}\text { - Professor e aluno dialogam sobre o material de estudo; } \\
\text { - Apresentação de vocabulário do nível a ser atingido; } \\
\text { - O professor deve perceber quais os conhecimentos anteriores do aluno sobre o } \\
\text { assunto a ser estudado. }\end{array}$ \\
\hline $\begin{array}{c}\text { Orientação Direta } \\
\text { (fase 2) }\end{array}$ & $\begin{array}{l}\text { - Os alunos exploram o assunto de estudo através do material selecionado pelo } \\
\text { professor; } \\
\text { - As atividades deverão proporcionar respostas específicas e objetivas. }\end{array}$ \\
\hline $\begin{array}{c}\text { Explicitação } \\
\text { (fase 3) }\end{array}$ & $\begin{array}{l}\text { - O papel do professor é o de observador; } \\
\text { - Os alunos trocam experiências, os pontos de vista diferentes contribuirão para cada } \\
\text { um analisar suas ideias. }\end{array}$ \\
\hline $\begin{array}{c}\text { Orientação Livre } \\
\text { (fase 4) }\end{array}$ & $\begin{array}{l}\text { - Tarefas constituídas de várias etapas, possibilitando diversas respostas, a fim de que } \\
\text { o aluno ganhe experiência e autonomia. }\end{array}$ \\
\hline $\begin{array}{c}\text { Integração } \\
\text { (fase 5) }\end{array}$ & $\begin{array}{l}\text { - O professor auxilia no processo de síntese, fornecendo experiências e observações } \\
\text { globais, sem apresentar novas ou discordantes ideias. }\end{array}$ \\
\hline \multicolumn{2}{|c|}{}
\end{tabular}
Fonte: Alves e Sampaio (2010, p. 71)

Assim sendo, quando o ensino é desenvolvido de acordo com essas fases de aprendizagem, há o favorecimento para a aquisição de um nível de pensamento em determinado conteúdo da geometria (Alves \& Sampaio, 2010). Ainda segundo esses autores, com exceção da última fase, as outras podem ocorrer em diversas ordens e até simultaneamente.

Conforme Nasser (1990), vários pesquisadores que já utilizaram esse modelo, assim como o próprio Van Hiele, afirmaram que é praticamente impossível o aluno no curso 
secundário $^{1}$ atingir o nível 5 (rigor). É neste nível que as geometrias não-euclidianas são compreendidas. Sendo assim, nas atividades da sequência didática que foram propostas em nossa investigação consideramos os quatro primeiros níveis do pensamento geométrico do Modelo proposto por Van Hiele, já que eles são os mais relevantes para a geometria que faz parte dos currículos de Matemática no Ensino Médio.

De forma resumida, entendemos que as fases de aprendizagem podem ser vistas como passos a serem seguidos pelo professor para organizar as atividades didáticas que serão conduzidas em sala de aula e para auxiliar os estudantes, visando que esses possam progredir de um nível para o próximo, como resultado da instrução deliberada, planejada e organizada.

\section{Delineamento da pesquisa e percurso metodológico}

A metodologia de pesquisa teve abordagem qualitativa, em que a professorapesquisadora manteve contato direto com o grupo de alunos pesquisado.

A nossa investigação deu-se por meio da pesquisa prática, ou ainda, pesquisa-ação, que é voltada para a intervenção em realidades sociais. É um tipo de investigação que tem sido utilizada com frequência para fazer referência a uma modalidade de pesquisa de intervenção na prática. E como Borba e Araújo (2012, p. 77) ressaltam, trata-se de, “[...] um processo investigativo de intervenção em que caminham juntas prática investigativa, prática reflexiva e prática educativa".

$\mathrm{Na}$ nossa investigação que envolveu o uso do software GeoGebra no ensino da Geometria Espacial, a sequência utilizada foi: Planejamento, Implementação e Avaliação. Nesse sentido, ainda segundo Tripp (2005, p. 453), fica evidente que o ato de planejar esse tipo de pesquisa deve ser feito "[...] tanto para a mudança na prática quanto para a avaliação dos efeitos da mudança na prática”.

Dessa forma, enfatizamos que a pesquisa-ação deu suporte à nossa investigação e contribuiu para darmos respostas à questão de pesquisa, por promover reflexões necessárias para o aprimoramento dos processos de ensino e de aprendizagem, produção de conhecimento e mudança da realidade.

\footnotetext{
${ }^{1}$ Atualmente usa-se Ensino Médio e não mais curso secundário.
} 
Considerando o Modelo de Van Hiele para o desenvolvimento do pensamento geométrico, elaboramos uma sequência de atividades que foi aplicada seguindo as fases de aprendizagem apresentadas no modelo: informação, orientação guiada, explicitação, orientação livre e integração. Assim, em cada unidade foram apresentadas sugestões de questionamentos para explorar os conhecimentos prévios dos alunos acerca dos conteúdos abordados (informação); foi exibido um guia de construção e planificação do objeto de estudo, com o uso do GeoGebra (orientação guiada), e foram propostas perguntas a fim de gerar reflexões sobre os resultados alcançados, visando que o aluno conseguisse explorar, investigar e elaborar conjecturas (explicitação e orientação livre). $\mathrm{Na}$ sequência, foram propostas atividades escritas para verificar a compreensão deles acerca dos conceitos adquiridos (integração).

A investigação foi realizada no primeiro semestre de 2018, em uma turma da $2^{\mathrm{a}}$ série do Ensino Médio, composta por 33 alunos, na faixa etária de 15 a 17 anos, em uma escola pública da cidade de Boa Vista, Roraima, Brasil. O projeto de pesquisa foi aprovado pelo Comitê de Ética em Pesquisa (CEP) da Universidade Estadual de Roraima, conforme Parecer Consubstanciado do CEP sob protocolo $\mathrm{n}^{\mathrm{o}} 2.638 .373 / 2018$.

A dinâmica das aulas consistiu em dois momentos: no primeiro momento ocorreu no Laboratório de Informática da escola, onde foram realizadas construções utilizando o software GeoGebra. No segundo momento, realizado em sala de aula, os alunos fizeram a socialização das construções obtidas, utilizando um projetor multimídia e resolveram as atividades escritas. Participaram desta pesquisa 30 alunos da turma, divididos em duplas, nomeadas por $\mathrm{D}_{1}, \mathrm{D}_{2}$, $\mathrm{D}_{3}, \ldots, \mathrm{D}_{15}$. Cada dupla recebeu a versão impressa do PE elaborado e as folhas avulsas com atividades propostas referentes a cada Unidade, para assim, fazerem o registro das respostas e devolverem para serem analisadas pela professora-pesquisadora.

Para a compreensão do significado das produções dos alunos, os registros coletados foram atentamente lidos, vistos e revistos a fim de identificar as principais informações e sistematizar as categorias e subcategorias que foram analisadas. O foco para direcionar a construção das categorias de análise foi a questão norteadora e os objetivos propostos para conduzir a nossa investigação podem ser encontrados na dissertação de Scalabrin (2019). 
Nesse artigo, o leitor vai encontrar a análise do processo de aprendizagem dos alunos sobre os conceitos de poliedros regulares, explorados na Unidade I do PE. O processo formativo que propusemos e desenvolvemos nessa Unidade teve por objetivos: utilizar o software GeoGebra para construir e planificar os cinco poliedros regulares; identificar vértices, faces e arestas nos mesmos; e obter a conjectura da relação de Euler. Assim, a partir do delineamento estabelecido, analisaremos na próxima seção, o desempenho dos estudantes por meio das construções realizadas no GeoGebra e dos registros escritos produzidos pelos alunos da turma investigada.

\section{Análise e discussão dos resultados}

As atividades propostas sobre os poliedros regulares foram planejadas e organizadas visando permitir que os alunos progredissem de um nível de pensamento geométrico para o seguinte, conforme o Modelo de Van Hiele. Optamos por iniciá-las com a construção e planificação das figuras utilizando o software GeoGebra, tendo em vista que os alunos reconhecessem as figuras visualmente por sua aparência global (nível 1). Posteriormente, os alunos foram orientados a analisarem as propriedades que as figuras apresentam e utilizarem a terminologia adequada para descrevê-las (nível 2). Em seguida, foram orientados a executar classificações lógicas das figuras por meio de suas propriedades (nível 3), a fim de que compreendessem a lógica formal do raciocínio, visando propor conjecturas (nível 4).

A primeira construção realizada foi a do Tetraedro (Atividade 1.1). Nesta atividade, os alunos ainda estavam se familiarizando com o GeoGebra. Algumas duplas não tinham participado do primeiro encontro, em que foram apresentados as noções básicas e os principais comandos do software. Por isso, nessa primeira construção, apresentamos com o auxílio do projetor multimídia as ferramentas que seriam utilizadas na construção e prestamos os esclarecimentos necessários para realizar as construções seguindo o passo a passo contido no material impresso que foi disponibilizado aos alunos.

Dando continuidade, cada dupla seguiu as instruções contidas na guia de construção, criaram um controle deslizante $i$ com valor mínimo 0 e valor máximo 1 e digitaram na caixa de entrada o Comando Planificação[Tetraedro[(0,0,0),(4,0,0), Eixoz],i]. Ao teclar Enter a construção foi visualizada em ambas as Janelas de Visualização 2D e 3D. Explicamos que, 
"Um sistema de coordenadas para o espaço é construído a partir de três eixos mutuamente perpendiculares e com uma origem comum" (Lima et al., 2006, p. 200). Mostramos que no Tetraedro construído o ponto $(0,0,0)$ está localizado na origem desses três eixos, que são nomeados por eixo x, eixo y, e eixo z. Na sequência, abordamos alguns procedimentos para obter uma melhor visualização do objeto construído, tais como ocultar eixos, malhas e plano, retirar rótulos dos elementos que compõem o objeto construído e modificar a cor. Finalizados esses passos, os alunos passaram a movimentar o controle deslizante, explorar as ferramentas Girar, Mover, Ampliar e Reduzir e observar as mudanças de visão da figura na Janela 3D.

Posteriormente, os alunos seguiram as orientações contidas no material impresso, e de forma análoga, realizaram as construções do Hexaedro (Atividade 1.2), Octaedro (Atividade 1.3), Dodecaedro (Atividade 1.4) e Icosaedro (Atividade 1.5). Apresentamos, na Figura 1, as produções realizadas por algumas duplas.

Figura 1: Poliedros Regulares construídos e planificados

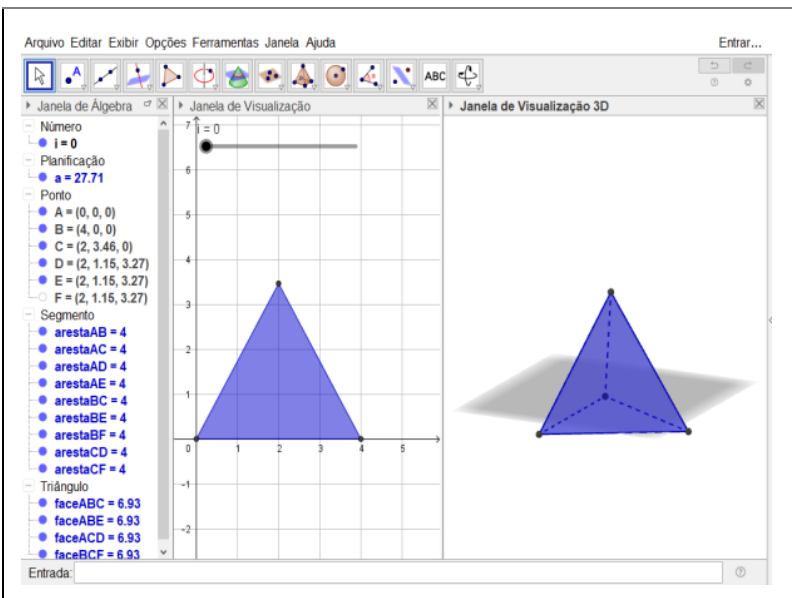

Tetraedro construído pela dupla $\mathrm{D}_{11}$

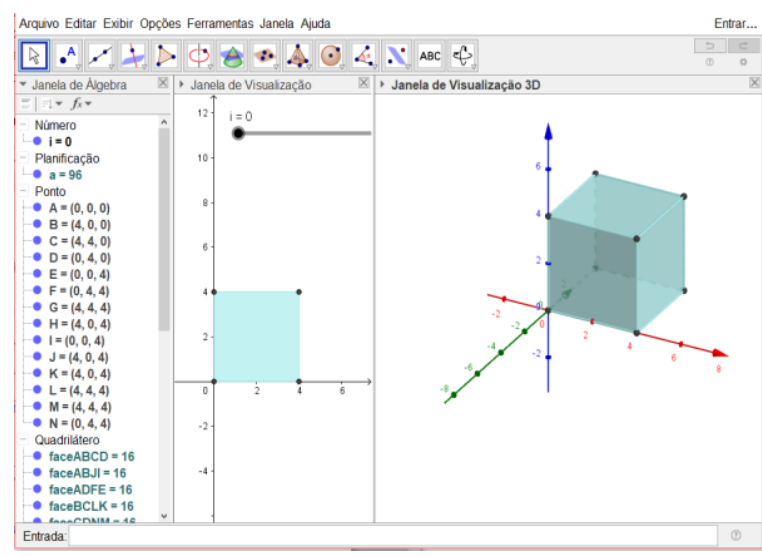

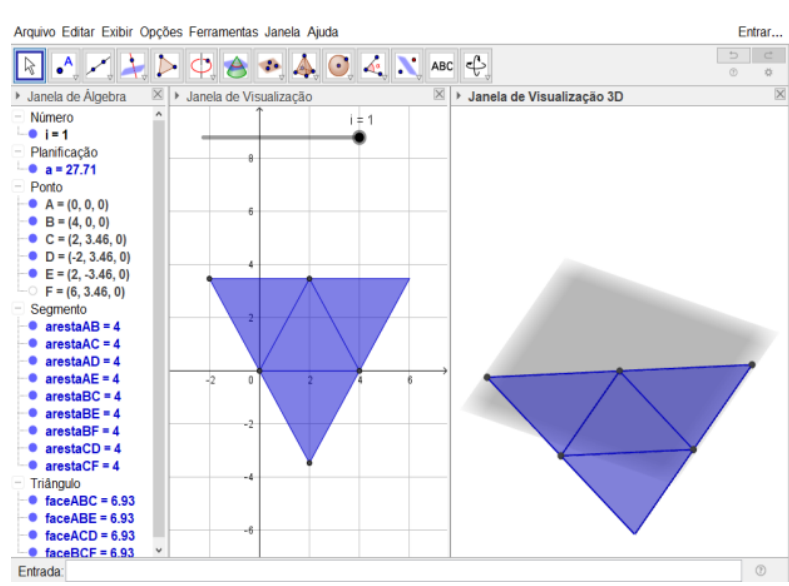

Tetraedro planificado pela dupla $\mathrm{D}_{11}$

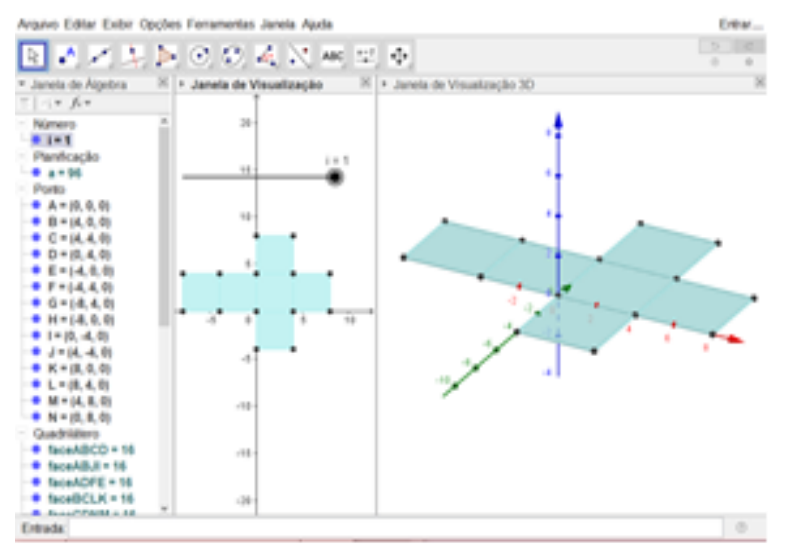




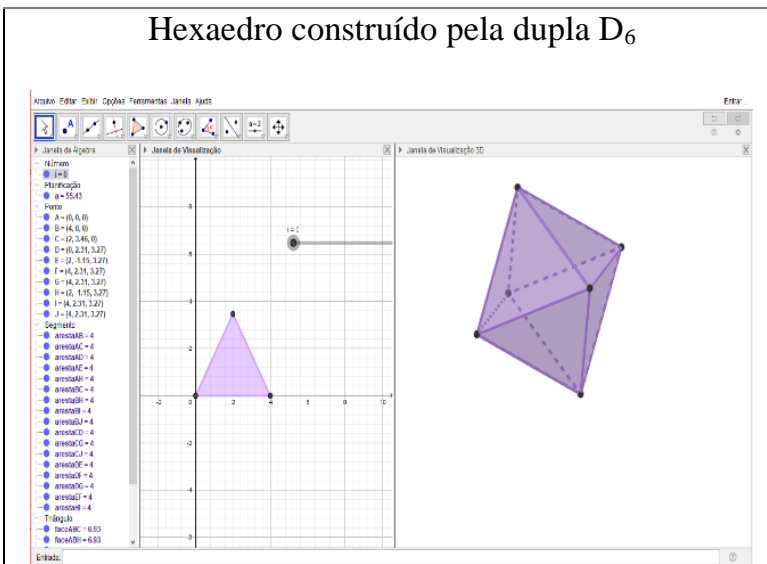

Octaedro construído pela dupla $\mathrm{D}_{8}$

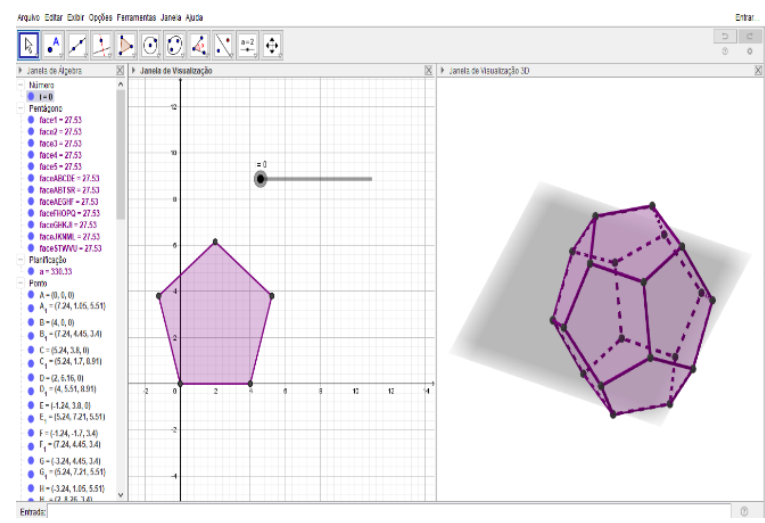

Dodecaedro construído pela dupla $\mathrm{D}_{13}$

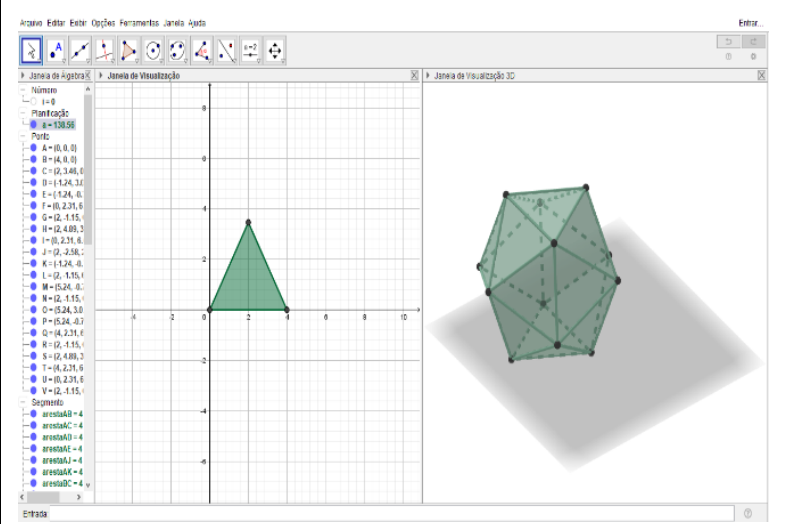

Icosaedro construído pela dupla $\mathrm{D}_{3}$
Hexaedro planificado pela dupla D6

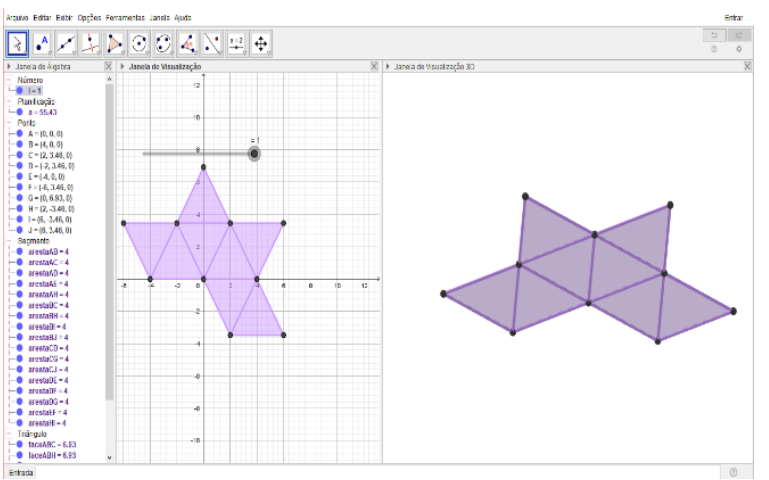

Octaedro planificado pela dupla D8

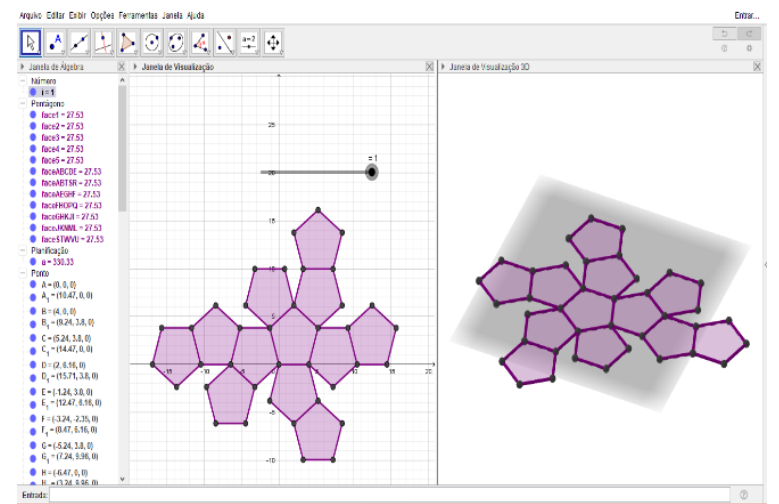

Dodecaedro planificado pela dupla $\mathrm{D}_{13}$

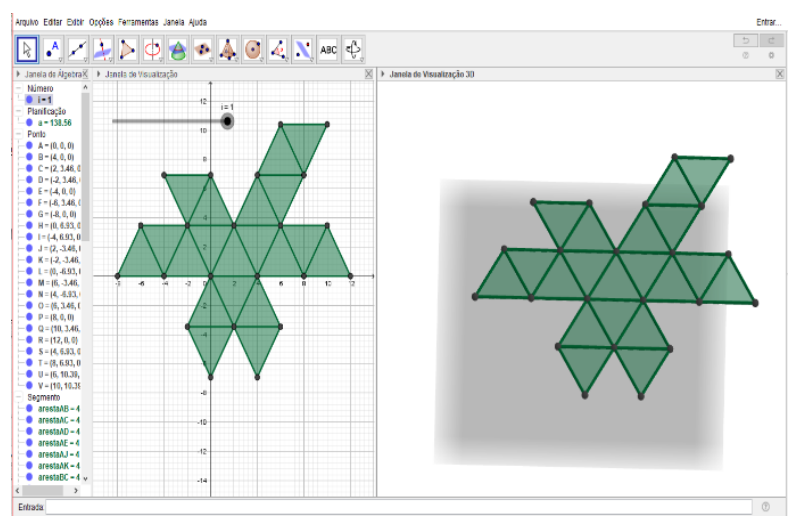

Icosaedro planificado pela dupla $\mathrm{D}_{3}$

Fonte: Produção dos alunos (2018)

A partir dessas construções, os alunos puderam investigar a quantidade de vértices, faces e arestas em cada poliedro construído, por meio da exploração visual e manipulação dinâmica dos objetos construídos, possibilitada pelo software GeoGebra. As potencialidades que o GeoGebra apresenta, com relação aos aspectos visuais, favorece meios para a 
experimentação com tecnologias. Segundo Borba et al. (2016, p. 54), "Mídias como estas participam de um coletivo que produz conhecimento, a partir das possibilidades de que experimentações sejam feitas com feedback visual quase instantâneo”. Dessa forma, evidenciamos que por meio da movimentação e da visualização dos objetos construídos, os alunos tiveram maior possibilidade para observar e reconhecer a quantidade de vértices, faces e arestas existente em cada poliedro.

Ao final de cada construção e planificação dos poliedros, os alunos registraram as respostas dos questionamentos apresentados no Quadro 3. Com esses questionamentos, buscou--se que ocorresse a transição do pensamento geométrico dos alunos, do nível 1 (visualização) para o nível 2 (análise), do Modelo de Van Hiele. Foram desenvolvidas cinco atividades escritas explorando os conceitos referentes aos poliedros regulares (Tetraedro, Hexaedro, Octaedro, Icosaedro e Dodecaedro).

\section{Quadro 3: Perguntas para gerar reflexões - Atividades 1.1; 1.2; 1.3; 1.4 e 1.5}

1. Ao manipular o controle deslizante que tipos de variações acontecem? Descreva o que ocorre na Janela de Visualização 3D com a construção obtida.

2. Posicione a bolinha do controle deslizante no valor 1, e responda:

2.1 Qual é o tipo de face da construção obtida?

2.2 Quantas faces, quantos vértices e quantas arestas a figura apresenta?

3. Você conhece algum objeto que apresente a forma semelhante à figura construída? Em caso positivo, cite exemplo(s).

Fonte: A Pesquisa (2020)

Verificou-se que 14 duplas entregaram as folhas com as atividades propostas resolvidas. Analisando as respostas obtidas na Atividade 1.1 (Tetraedro) foi possível verificar que todas as duplas (100\%) conseguiram descrever o que ocorre com a construção obtida na Janela de Visualização 3D, ao mover o controle deslizante. Destacamos o comentário da dupla $\mathrm{D}_{8}$, ao afirmar que: "Ao mover o mouse, quando $i=0$, a figura se torna uma construção espacial e quando $i=1$, a figura se torna plana". Ao serem questionados sobre o tipo de face obtida, dez duplas $(71,4 \%)$ responderam "face triangular", e quatro duplas $(28,6 \%)$ afirmaram "construção plana". No que se refere à quantidade de faces, vértices e arestas que o Tetraedro apresenta, treze duplas $(92,9 \%)$ responderam corretamente, " 4 faces, 4 vértices e 6 arestas". Ao serem interrogados se conheciam algum objeto que apresentasse a forma semelhante à figura construída e citassem exemplo(s), em caso positivo, verificamos nas 
respostas apresentadas que onze duplas $(78,6 \%)$ responderam “sim”, e os exemplos mais citados foram "pirâmide" e "brinquedo de criança".

No que diz respeito à análise da Atividade 1.2 (Hexaedro), constatou-se que ao serem questionados sobre o tipo de face obtida na figura construída, dez duplas $(71,4 \%)$ responderam "face quadrangular”, duas (14,3\%) afirmaram "espacial”, e outras duas (14,3\%) registraram “cubo”. Com relação à quantidade de faces, vértices e arestas que o Hexaedro apresenta, onze duplas $(78,6 \%)$ responderam corretamente, "6 faces, 8 vértices e 12 arestas". Ao serem interrogados se conheciam algum objeto que apresentasse a forma semelhante à figura construída e citassem exemplo(s), em caso positivo, observamos nas respostas apresentadas que onze duplas $(78,6 \%)$ responderam “sim”, e os exemplos mais citados foram “dados”, “cubo de gelo", “cubo mágico” e "caixa de presente”.

Com os dados obtidos na Atividade 1.3 (Octaedro), observou-se que ao serem questionados sobre o tipo de face obtida na figura construída, treze duplas (92,9\%) responderam “face triangular”, e uma $(7,1 \%)$ não respondeu ao questionamento. Com relação à quantidade de faces, vértices e arestas que o Octaedro apresenta, nove duplas $(64,3 \%)$ responderam corretamente, "8 faces, 6 vértices e 12 arestas". Ao serem interrogados se conheciam algum objeto que apresentasse a forma semelhante à figura construída e citassem exemplo(s), em caso positivo, examinamos nas respostas apresentadas que treze duplas $(92,9 \%)$ responderam "sim", $e$ os exemplos citados foram "balão de festa junina" $e$ "diamante".

Observando os resultados obtidos na Atividade 1.4 (Dodecaedro), aferiu-se que ao serem questionados sobre o tipo de face obtida na figura construída, treze duplas $(92,9 \%)$ responderam “face pentagonal” e uma $(7,1 \%)$ não respondeu o questionamento. Com relação à quantidade de faces, vértices e arestas que o Dodecaedro apresenta, dez duplas $(71,4 \%)$ responderam corretamente, "12 faces, 20 vértices e 30 arestas". Ao serem interrogados se conheciam algum objeto que apresentasse a forma semelhante à figura construída e citassem exemplo(s), em caso positivo, verificamos nas respostas apresentadas que nove $(64,3 \%)$ responderam "sim”, e os exemplos mais citados foram "dados de RPG" e "bola de futebol".

Com relação aos dados obtidos na Atividade 1.5 (Icosaedro), verificou-se que ao serem questionados sobre o tipo de face obtida na figura construída, doze duplas $(85,7 \%)$ 
responderam "face triangular", e duas (14,3\%) não responderam à questão. No questionamento sobre a quantidade de faces, vértices e arestas que o Icosaedro apresenta, oito $(57,1 \%)$ responderam corretamente, "20 faces, 12 vértices e 30 arestas". Ao serem interrogados se conheciam algum objeto que apresentasse a forma semelhante à figura construída e citassem exemplo(s), em caso positivo, constatamos que apenas quatro duplas $(28,6 \%)$ responderam "sim", e os exemplos citados foram "pedras em bijuterias" e "tampa de perfume".

Os resultados acima sinalizam que ao desenvolverem essas atividades por meio da manipulação e da visualização das construções realizadas com o uso do software GeoGebra, a maioria dos alunos conseguiram analisar corretamente as propriedades dos poliedros construídos, e ainda, relacioná-las com objetos do cotidiano. Assim, acreditamos que a manipulação direta na tela do computador com os poliedros construídos, favoreceram a análise imediata das construções e contribuíram para o desenvolvimento dos conceitos referentes aos poliedros regulares (Tetraedro, Hexaedro, Octaedro, Icosaedro e Dodecaedro).

Para finalizar a Unidade de poliedros regulares, propusemos a Atividade 1.6, que é apresentada no Quadro 4.

Quadro 4: Atividade 1.6

1. Preencha a tabela a seguir com base nas anotações feitas sobre a construção e planificação dos cinco poliedros regulares.

\begin{tabular}{|l|l|l|l|l|}
\hline Nome do poliedro & Tipo de face & Quant. de vértices & Quant. de faces & Quant. de arestas \\
\hline & & & & \\
\hline & & & & \\
\hline & & & & \\
\hline & & & & \\
\hline & & & & \\
\hline
\end{tabular}

2. Pode-se estabelecer alguma relação entre a quantidade de vértices $(\mathrm{V})$, faces $(\mathrm{F})$ e arestas (A) de um poliedro regular? (Dica: Some $V+F$ e compare com A)

3. Conjecture a relação encontrada. (Obs.: Uma conjectura é uma ideia, fórmula ou frase, a qual não foi provada ser verdadeira, baseada em suposições ou ideias com fundamento não verificado).

4. Fotografe ou pesquise fotos (em jornais, revistas ou na internet) de objetos e construções que lembrem poliedros. (Salve a imagem e encaminhe o arquivo para a professora-pesquisadora).

Fonte: A Pesquisa (2020) 
Essa atividade foi elaborada visando que os alunos explorassem as construções dos poliedros para obter a conjectura da Relação de Euler: "Em todo poliedro com A arestas, V vértices e F faces, vale a relação V $-\mathrm{A}+\mathrm{F}=2$ ” (Lima et al., 2006, p. 235). Na verdade, segundo o referido autor, a Relação de Euler é verdadeira apenas para os poliedros convexos, mas o enunciado dessa relação costuma fascinar os alunos quando tomam contato com ele pela primeira vez.

Com a Atividade 1.6, buscou-se criar possibilidades para que ocorresse a transição do pensamento geométrico dos alunos do nível 2 para o nível 3, e do nível 3 para o nível 4, do Modelo Van Hiele. Verificamos, com os dados obtidos, que dez duplas $(71,4 \%)$ conseguiram preencher corretamente a tabela apresentada da questão 1, nomeando o poliedro, identificando o tipo de face que apresenta e indicando a quantidade de vértices, faces e arestas, como mostra a Figura 2, produzido pela Dupla $\mathrm{D}_{6}$.

Figura 2: Atividade 1.6 - Resolução da questão 1

\begin{tabular}{|c|c|c|c|c|}
\hline $\begin{array}{l}\text { Nome do } \\
\text { Poliedro }\end{array}$ & Tipo de face & $\begin{array}{l}\text { Quant. de } \\
\text { vértices }\end{array}$ & $\begin{array}{l}\text { Quant. de } \\
\text { faces }\end{array}$ & $\begin{array}{l}\text { Quant. de } \\
\text { arestas }\end{array}$ \\
\hline Gra dino & trianawlour & 4 váutices & 4 laces & Go areste \\
\hline edno & auadranoula & 8 winti & $6 \mathrm{bc}$ & $12 \mathrm{lar}$ \\
\hline eta & truaven & - oveêtices & 8 Laces & 32 ar \\
\hline Anoreres & pentagenal & 20 neértices & 12 taces & 30 areatos \\
\hline Iursardaro & tr & 12 veirtices & 20 baces & 30 arestos \\
\hline
\end{tabular}

Fonte: Produção da Dupla $\mathrm{D}_{6}$ (2018)

Em relação à segunda questão "Pôde-se estabelecer alguma relação entre a quantidade de vértices $(V)$, faces $(F)$ e arestas $(A)$ de um poliedro regular?", verificamos que nove duplas $(64,3 \%)$ concluíram que sim. Destacamos a resposta apresentada por $\mathrm{D}_{10}$, que afirmou "Sim. Quando somamos o número de vértices com o número de faces que cada poliedro possui e comparamos com a quantidade de arestas, a diferença é sempre 2". Também, constatamos que nove duplas $(64,3 \%)$ conseguiram encontrar corretamente a conjectura da Relação de Euler, ao afirmar que $\mathrm{V}+\mathrm{F}=\mathrm{A}+2$. 
Com esses resultados consideramos que o desempenho dos alunos investigados foi bastante satisfatório, pois a Relação de Euler foi obtida corretamente por 64,3\% dos participantes. Acreditamos que esse desempenho deve-se principalmente ao design das atividades propostas que permitiu a exploração visual e manipulação dinâmica dos objetos construídos no GeoGebra para formalizar os conceitos. Ao nosso olhar, o uso do software aliado as atividades propostas de cunho exploratório e investigativo, favoreceu para que o processo de aprendizagem dos alunos sobre os conceitos de poliedros regulares ocorresse de forma gradativa, partindo da informação visual dos objetos construídos e análise das propriedades, para a compreensão da lógica formal da Relação de Euler. Dessa forma, conforme afirmam Santos e Nacarato (2014, p. 38), “A aprendizagem dos alunos se dá num movimento contínuo de significações, passando de movimentos intuitivos para generalizações mais abstratas".

Além disso, diante das respostas apresentadas sinalizamos que os estudantes entenderam a proposta metodológica apresentada na Unidade I e, acreditamos assim como pontua Pazuch $(2014$, p. 118), “[...] que o uso do software pode potencializar a construção e a validação da Relação de Euler”. Corroboramos ainda, e em conformidade com Chiele (2007), que o desenvolvimento do pensamento geométrico do aluno depende em grande parte da observação do professor ao orientar as discussões e as tarefas a serem realizadas.

Acreditamos que o design das atividades propostas, ofereceu caminhos propícios para que os alunos explorassem os objetos construídos no GeoGebra e desenvolvessem o pensamento geométrico passando pelos quatro primeiros níveis de aprendizagem do Modelo de Van Hiele. Como se pôde constatar, as atividades propostas iniciaram com a construção do objeto (nível 1 - visualização). Posteriormente, os alunos foram conduzidos a perceber características dos objetos construídos e identificar algumas propriedades (nível 2 - análise). Em seguida, os alunos realizaram classificações lógicas das figuras por meio de suas propriedades (nível 3 - ordenação ou classificação). Por fim, os alunos apresentaram capacidade de compreender o processo dedutivo, nos conceitos estudados, elaborando conjecturas (nível 4 - dedução formal). 


\section{Considerações Finais}

O intuito deste artigo foi apresentar parte dos resultados de uma pesquisa de mestrado, cujo objetivo foi investigar as contribuições do software GeoGebra 3D para os processos de ensino e de aprendizagem de conteúdos de Geometria Espacial no Ensino Médio, seguindo os pressupostos teóricos do Modelo de Van Hiele. Para tanto, apresentamos análise do processo de aprendizagem dos conceitos de poliedros regulares, realizada por meio dos arquivos digitais de construções de poliedros por meio do software GeoGebra e registros escritos referentes às atividades realizadas durante a investigação.

Com base nas produções analisadas, evidenciamos que o uso do software GeoGebra aliado as atividades propostas de cunho exploratório e investigativo, favoreceu para que o processo de aprendizagem dos alunos sobre os conceitos de poliedros ocorresse de forma gradativa, partindo da informação visual dos objetos construídos e análise das propriedades, para a compreensão da lógica formal e elaboração de conjecturas.

Ao nosso ver, inferimos que o uso do software GeoGebra contribuiu para os processos de ensino e de aprendizagem dos conteúdos ministrados, pois os alunos demonstraram interesse em realizar as construções e tiveram comprometimento em resolver as atividades escritas. Isso mostra, de acordo com Baldini (2014), que explorar as potencialidades do software GeoGebra para obter construções dinâmicas, favoreceu que os estudantes investigados reconhecessem o potencial do software para percepção de regularidades e descobertas de conjecturas. Além disso, evidenciamos como constatado por Silveira e Bisognin (2008, p. 7), que "[...] o uso de recursos computacionais auxiliou os alunos a serem mais autônomos, pois possibilitou construir e visualizar os sólidos geométricos oportunizando a descoberta das propriedades e a exploração de suas relações".

Além disso, acreditamos que o ambiente apresentado na tela do computador com software GeoGebra permitiu que os alunos observassem diversos exemplos e estabelecessem conjecturas, sendo preparado para a compreensão de conceitos e aprendizado matemático. Borba e Penteado (2017) apontam que usar softwares de matemática dinâmica torna-se um importante aliado nos processos de investigação, pois possibilita a experimentação, além de estimular a percepção visual do aluno. 
Notamos, ainda, que o design das atividades propostas favoreceu a inserção das TD e ofereceu caminhos propícios para que os alunos se apropriassem do conhecimento, desenvolvendo habilidades de visualização espacial, evoluindo nos níveis progressivos do Modelo de Van Hiele.

É importante ressaltar que, voltando o nosso olhar à investigação realizada, o papel desempenhado pela pesquisadora foi fundamental, pois as práticas pedagógicas foram reorganizadas ao propor tarefas exploratórias e investigativas com o uso de tecnologias digitais. Dessa maneira, a integração entre currículo e tecnologia pôde conduzir transformações na aprendizagem, nas diretrizes de ensino e nas ações de docentes e discentes, valorizando a formação de conceitos e contribuindo para modificar as práticas de ensino tradicional vigente (Borba \& Penteado, 2017).

Concluímos reafirmando que o uso do software GeoGebra contribuiu para a promover o avanço do pensamento geométrico dos alunos investigados, em relação aos conceitos estudados de poliedros, desde o nível 1 (visualização) até o nível 4 (dedução formal) do Modelo Van Hiele. Na análise da atividade realizada, nosso foco não foi aplicar testes para verificar os níveis de aprendizagem em que os alunos se encontravam, de acordo com o Modelo de Van Hiele. Mas, foi propor atividades que proporcionassem evolução pelos níveis propostos no Modelo, em relação aos conceitos estudados.

\section{Referências}

Abar, C. A. A. P. \& Cotic, N. S. (2014). GeoGebra na produção do conhecimento matemático. Iglu.

Alves, G. S. \& Sampaio, F. F. (2010). O modelo de desenvolvimento do pensamento geométrico de Van Hiele e possíveis contribuições da geometria dinâmica. Revista de $\begin{array}{lllll}\text { Sistemas de Informação } & \text { da } & \text { FSMA, }\end{array}$ http://www.fsma.edu.br/si/edicao5/FSMA_SI_2010_1_Principal_2.html.

Baldini, L. A. F. (2014). Elementos de uma comunidade de prática que permitem o desenvolvimento profissional de professores e futuros professores de matemática na utilização do software Geogebra [tese de doutorado, Universidade Estadual de Londrina]. Biblioteca Digital Brasileira de Teses e Dissertações. http://bdtd.ibict.br/vufind/Record/UEL_efc5365fc2f32b83bfa4e3b5e7345868.

Bonotto, A. K. \& Bisognin, E. (2015). Contribuições de um Objeto de Aprendizagem e dos Registros de Representações Semióticas no Estudo da Função Exponencial. Revista Renote: Novas Tecnologias na Educação, https://seer.ufrgs.br/renote/article/view/61443. 
Borba, M. C. \& Araújo, J. L. (2012). Pesquisa Qualitativa em Educação Matemática. Autêntica Editora.

Borba, M. C. \& Penteado, M. G. (2017). Informática e Educação Matemática. Autêntica Editora.

Borba, M. C., Scucuglia, R. R. S. \& Gadanidis, G. (2016). Fases das tecnologias digitais em Educação Matemática: Sala de aula e internet em movimento. Autêntica Editora.

Chiele, J. N. (2007). A geometria no ensino médio: Um estudo sobre o desenvolvimento dos conceitos de comprimento, área e volume [dissertação de mestrado, Universidade Luterana do Brasil]. Teses e Dissertações do Programa de Pós-Graduação em Ensino de Ciências e http://www.ppgecim.ulbra.br/teses/index.php/ppgecim/article/view/66.

Giraldo, V. (2012). Integrando Geometria e Funções: Gráficos dinâmicos. Revista do Professor de Matemática, (79), 39-46. http://www.rpm.org.br/cdrpm/79/10.html.

Lima, E. L., Carvalho, P. C. P., Wagner, E. \& Morgado, A. C. (2006). A matemática do Ensino Médio (volume 2, 6.a edição). SBM (Original publicado em 1997).

Meira, G. G. (2015). Comunicação e resolução de problemas utilizando o modelo Van Hiele para a exploração geométrica em sala de aula [dissertação de mestrado, Universidade Estadual da Paraíba]. Teses e Dissertações do Programa de Pós-Graduação Mestrado Profissional em Ensino de Ciências e Matemática. http://posgraduacao.uepb.edu.br/ppgecm/download/disserta\%C3\%A7\%C3\%B5es/mestrado_pro fissional/2015/Dissertacao-GILMARA-MEIRA.pdf.

Nasser, L. (1990). O desenvolvimento do raciocínio em Geometria. Boletim GEPEM, 15(27), 93-99. http://costalima.ufrrj.br/index.php/gepem/article/view/46/28.

Nasser, L. \& Vieira, E. R. (2015). Formação de Professores em Geometria: Uma experiência no ciclo de alfabetização. Revista Vidya, 35(2), 19-36. https://periodicos.ufn.edu.br/index.php/VIDYA/article/view/600.

Pazuch, V. (2014). Cyberformação semipresencial: A relação com o saber de professores que ensinam matemática [tese de doutorado, Universidade Luterana do Brasil]. Teses e Dissertações do Programa de Pós-Graduação em Ensino de Ciências e Matemática. http://www.ppgecim.ulbra.br/teses/index.php/ppgecim/article/view/215.

Pereira, T. L. M. (2012). O uso do software GeoGebra em uma escola pública: Interações entre alunos e professor em atividades e tarefas de geometria para o ensino fundamental e médio [dissertação de mestrado, Universidade Federal de Juiz de Fora]. Biblioteca Digital Brasileira de Teses e Dissertações. http://bdtd.ibict.br/vufind/Record/UFJF_dbec1761dbd59084892e3569b4701d5e.

Santos, C. A. \& Nacarato, A. M. (2014). Aprendizagem em Geometria na educação básica: A fotografia e a escrita na sala de aula. Autêntica Editora.

Scalabrin, A. M. M. O. (2019). Geometria espacial com o software GeoGebra 3D: análise dos processos de ensinar e de aprender no ensino médio [dissertação de mestrado, Universidade Estadual de Roraima]. Programa de Pós-Graduação em Ensino de Ciências.

https://uerr.edu.br/ppgec/wp- 
content/uploads/2019/07/Disserta\%C3\%A7\%C3\%A3o_Ana-Maria-Mota-OliveiraScalabrin.pdf.

Silveira, A. M. \& Bisognin, E. (2008) O uso de programas computacionais como recurso auxiliar para o ensino de Geometria Espacial. IV Colóquio de História e Tecnologia no Ensino De Matemática, (pp. 1-8). Rio de Janeiro, Brasil. https://docplayer.com.br/17986248-O-uso-de-programas-computacionais-comorecurso-auxiliar-para-o-ensino-de-geometria-espacial.html.

Tripp, D. (2005). Pesquisa-ação: Uma introdução metodológica. Revista Educação e Pesquisa, 31(3), 443-466. $\quad$ https://www.scielo.br/scielo.php?pid=S1517$97022005000300009 \&$ script=sci_abstract\&tlng=pt.

Villiers, M. (2010). Algumas reflexões sobre a Teoria de Van Hiele. Revista Educação Matemática Pesquisa, $12(3)$ 400-431. https://revistas.pucsp.br/index.php/emp/article/view/5167.

\section{Autoras}

Ana Maria Mota Oliveira Scalabrin

Mestra em Ensino de Ciências pela Universidade Estadual de Roraima (Brasil). Professora de Matemática na rede estadual de ensino de Roraima (Brasil). Temas de pesquisa: Métodos Pedagógicos e Tecnologias Digitais no Ensino de Ciências. E-mail: anamscalabrin@gmail.com

Solange Mussato Doutora em Ensino de Ciências e Matemática pela Universidade Luterana do Brasil. Professora permanente no Ensino de Ciências da Universidade Estadual de Roraima. Coordenadora de matemática na Secretaria de Educação do Estado de Roraima. Temas de pesquisa: Tecnologias Digitais; Formação de Professores; Distância Educacional. E-mail: solangemussato1@yahoo.com.br 